\title{
Is Hand Plucking an Accurate Method of Estimating Bite Mass and Instantaneous Intake of Grazing Herbivores?
}

\author{
Olivier Bonnet, ${ }^{1}$ Nicole Hagenah, ${ }^{1,2}$ Lisa Hebbelmann, ${ }^{3}$ Michel Meuret, ${ }^{4}$ and Adrian M. Shrader ${ }^{5}$
}

Authors are ${ }^{1}$ Postdoc Researcher, ${ }^{3}$ MSc student, ${ }^{5}$ Research Lecturer, School of Biological and Conservation Sciences, University of KwaZulu-Natal, Pietermaritzburg 3209, South Africa; ${ }^{2}$ Postdoc Researcher, Department of Ecology and Evolutionary Biology, Yale University, New Haven, CT 06520, USA; and ${ }^{4}$ Research Director, French National Institute for Agricultural Research, UMR Livestock Systems Dynamics in Mediterranean and Tropical Environments, Campus international de Baillarguet, 34398 Montpellier Cedex 5, France.

\begin{abstract}
Instantaneous intake is central to the understanding of large herbivore foraging strategies and rangeland ecology. Unfortunately, its measurement under field conditions remains challenging because of the difficulty of estimating bite mass. The hand plucking method provides a simple, noninvasive method of estimating bite masses and thus instantaneous intake of grazing herbivores. However, many authors questioned its accuracy and interobserver repeatability. In this study, we tested the accuracy and the repeatability of the hand plucking method using four observers and two herbivore species (i.e., cattle and goats). We compared hand plucked bite mass estimates to actual bite mass of bites taken by the herbivores on natural patches of grass. Training of the observers was fundamental to obtaining accurate bite mass measurements. The mean daily accuracy of the observers' bite mass estimates increased from $60-80 \%$ to $80-94 \%$ within $5 \mathrm{~d}$. After training, the relationship between bite mass estimates and actual bite mass was linear and not significantly different from a $\mathrm{Y}=\mathrm{X}$ relationship. This means that individual bite mass estimates were centered on the real values and thus positive and negative errors canceled each other when combined. As a result, estimates of cumulative intake over about 10 feeding stations had accuracies of over $95 \%$. Furthermore, neither the observer identity nor the herbivore species affected the accuracy of the measurements. The categorization of bites into different size categories proved to be essential in achieving accurate measurements. When observers are trained, hand plucking is a reliable and accurate method of estimating bites mass and instantaneous intake of grazing herbivores. This has important implications for rangeland research and management, as hand plucking is often the only practicable method available for estimating instantaneous intake of freeranging herbivores.
\end{abstract}

\section{Resumen}

El consumo instantáneo es central para la comprensión de las estrategias de pastoreo de los grandes herbívoros y para la ecología de los pastizales naturales. Desafortunadamente, medirla bajo las condiciones de campo sigue siendo un desafío debido a la dificultad de calcular la masa por bocado. La cosecha manual ("hand plucking") proporciona una muestra no-invasiva para poder estimar la masa del bocado y el consumo instantáneo de los herbívoros. Sin embargo, muchos autores cuestionan su exactitud y la uniformidad de los resultados entre observadores. En este estudio, probamos la exactitud y la subjetividad del método de la cosecha manual usando cuatro observadores y dos especies de herbívoros (vacunos y caprinos). Se compararon las cosechas manuales de masa por bocado con la masa de bocado real, hechas por herbívoros en parches de pasto natural. El entrenamiento fue fundamental para obtener medidas exactas de masa por bocado. La exactitud promedio diaria de la masa por bocado estimada aumentó de $60-80 \%$ a $80-94 \%$ en el plazo de 5 días. Después del entrenamiento, la relación entre la masa por bocado estimada y la masa por bocado real fue lineal y no significativamente diferente de una relación en la que $\mathrm{X}=\mathrm{Y}$. Esto quiere decir que las estimaciones individuales de masa de bocado estuvieron centradas en los valores reales y que por lo tanto los errores positivos y negativos tendieron a contrarrestarse. Consecuentemente, la estimación de consumo acumulado a lo largo de 10 estaciones de pastoreo tuvo una exactitud superior al 95\%. Además, la exactitud de las estimaciones no estuvieron afectadas por los observadores ni por la especie de herbívoro. La clasificación de los bocados en diversas categorías de tamaño, fue esencial para el logro de estimaciones exactas. Cuando se cuenta con observadores entrenados, el método de cosecha manual es un método confiable y preciso para la estimación de masa de bocado y el consumo instantáneo de los herbívoros. Esto tiene implicancias importantes para la investigación y el manejo de pastizales naturales, debido a que la cosecha manual es a menudo el único método disponible, para la estimación del consumoinstantáneo de los herbívoros en pastoreo.

Key Words: bite size, coding grid, direct observation, free-ranging herbivores, foraging strategy, functional response

Research was funded by the University of KwaZulu-Natal, South Africa, and the National Research Foundation of South Africa.

Correspondence: Olivier Bonnet, School of Biological and Conservation Sciences, University of KwaZulu-Natal, Pietermaritzburg 3209, South Africa. Email: odbonnet@hotmail.fr

Manuscript received 17 December 2010; manuscript accepted 22 March 2011.

\section{INTRODUCTION}

Food intake is a central variable in many grazing studies. At a daily scale, intake is used to understand and predict animal performance or productivity in both ecological (Sinclair 1975; Illius and Gordon 1987) and agricultural studies (Burns et al. 
1994; Forbes 1995). At the instantaneous scale, intake provides a direct measurement of the animal's ability to obtain dry matter and nutrients on a particular vegetation type. This measurement is particularly useful to understand foraging constraints and the mechanisms linking vegetation properties to feeding choices and habitat use (Stephens and Krebs 1986; Spalinger and Hobbs 1992; Shipley et al. 1994).

Unfortunately, the measurement of food intake is quite challenging, particularly in heterogeneous grasslands and rangelands (Cordova et al. 1978; Leaver 1982; Gordon 1995; Decruyenaere et al. 2009). The ratio among fecal output and diet indigestibility (Le Du and Penning 1982), and the use of plant markers, particularly n-alkanes (Mayes et al. 1986; Dove and Mayes 1996) are two relatively successful methods used to estimate daily intake (Gordon 1995; Mayes and Dove 2000). However, these methods require a representative sample of the animal's diet in order to determine its digestibility (ratio method) or its natural concentration in n-alkanes (n-alkanes method). Collecting these samples prove to be challenging when animals feed in highly heterogeneous environments, thus limiting the applicability of these techniques with free-ranging herbivores (Vulich et al. 1993; Mayes and Dove 2000).

Problems related to the estimation of instantaneous intake are mostly related to the difficulty in estimating bite mass. Currently, only a few methods can be used to estimate bite mass of free-ranging herbivores. Esophageal fistulation is generally believed to give the most accurate results (Torell 1954; Stobbs 1973). However, it is invasive, expensive to maintain, not practicable for free-ranging wild herbivores, and ultimately raises the question of animal welfare. A second option is the direct measurement of bite imprints left by herbivores as they feed (e.g., length $\times$ width $\times$ height). This method has been successfully applied to free-ranging herbivores, but requires representative bite samples to be collected to relate bite mass to bite volume and bulk density (Shrader et al. 2006). A third method, hand plucking, consists of manually collecting plant material by simulating the bite size, plant species, and plant parts taken by the animal (Halls 1954; Cook 1964). Advantages of this method are that it is simple, causes minimal disturbance to the animal, and can produce large data sets at minimal cost. As a result, it has been commonly used for estimating bite mass in field studies with both wild (Collins and Urness 1983; Renecker and Hudson 1985; Hudson and Frank 1987; Okello et al. 2002) and domestic herbivores (Hobbs et al. 1983; Agreil and Meuret 2004; Agreil et al. 2006).

Although particularly promising for field studies, the hand plucking method has often been criticized for its subjectivity (e.g., Cook 1964; Langlands 1974; Jiang and Hudson 1992). In particular, it has been suggested that bite mass estimations may be biased and that there may be a low degree of interobserver repeatability (e.g., Gordon 1995; Forbes 2006). To explore this, several experiments tested the reliability of hand plucking for the measurement of daily intake (Meuret et al. 1985; Renecker and Hudson 1985; Gedir and Hudson 2000). Reliability was generally high (i.e., over $90 \%$ ), but the product of bite mass (determined by hand plucking), bite rate, and grazing time consistently overestimated intake. It is, however, unclear whether this discrepancy was the result of overestimating either bite mass or the average bite rate over the day.
To our knowledge, only one study has compared bite mass estimated by hand plucking to a less subjective method, in this case fistulation. Using esophageal fistulated steers grazing in natural grasslands, Wallis de Vries (1995) reported a good relationship, although nonlinear, among the two methods. However, the study did not directly measure the accuracy of the hand plucked bites. Furthermore, it did not test the repeatability of the technique, as only one observer was involved. To address these shortcomings, we conducted an experiment to evaluate the accuracy and repeatability of hand plucking to estimate the bite masses of herbivores grazing in heterogeneous grasslands. Specifically, we tested 1) the accuracy and bias of bite mass estimated by hand plucking at the feeding station scale, 2) the importance of observer training with regard to the accuracy of the estimations, 3) interobserver repeatability, and 4) whether the accuracy of the bite mass estimates varied between different sized herbivores (i.e., goats and cattle).

\section{METHODS}

We conducted the experiment from January to April 2010 (summer rainy season) at the Ukulinga Research Farm of the University of KwaZulu-Natal, South Africa. To determine the accuracy of hand plucking, we compared hand plucked bite mass estimates to measurements made using natural patches of grass weighed before and after presentation to the herbivores (Fleurance et al. 2009). Throughout the experiment, we used four adult Jersey cows (Bos taurus taurus) and four indigenous goats (Capra hircus). This provided us with herbivores of different body sizes and feeding habits, which could then reflect the feeding of a wide range of domestic or wild grazing herbivores. The experiment involved four observers. Two of them (observers 1 and 3) had conduced years of research on the foraging of wild herbivores and thus were well trained in direct observation. They were, however, untrained with respect to observing the feeding behavior of cattle and goats. The two remaining observers ( 2 and 4 ) have never been involved in herbivore foraging observations before the study.

\section{Preparation of the Natural Patches of Grass}

To simulate natural sward conditions, we dug up patches of natural rangeland. The patch dimensions $(35 \times 50 \mathrm{~cm})$ roughly represent the size of a feeding station for a goat and a portion of a feeding station for a cow. For each patch, the soil layer was approximately $12 \mathrm{~cm}$ deep. Grass species included mostly hairy trident grass (Tristachya leucothrix Nees), large seed setaria (Setaria nigrirostris Nees), and weeping lovegrass (Eragrostis curvula Nees). Sward height ranged from $20 \mathrm{~cm}$ to $50 \mathrm{~cm}$. We prepared the patches every morning, about $2 \mathrm{hr}$ prior to the start of the experiments. We then put these patches into plastic trays of the same dimensions. The final combined mass of the patches and trays ranged between $12 \mathrm{~kg}$ and $19 \mathrm{~kg}$.

\section{Experimental Design}

Training of the Observers. As suggested by Agreil and Meuret (2004), we developed species-specific coding grids to help the observers categorize bites with regard to mass (Fig. 1). We based the categories ( $n=16$ for each herbivore species) on 


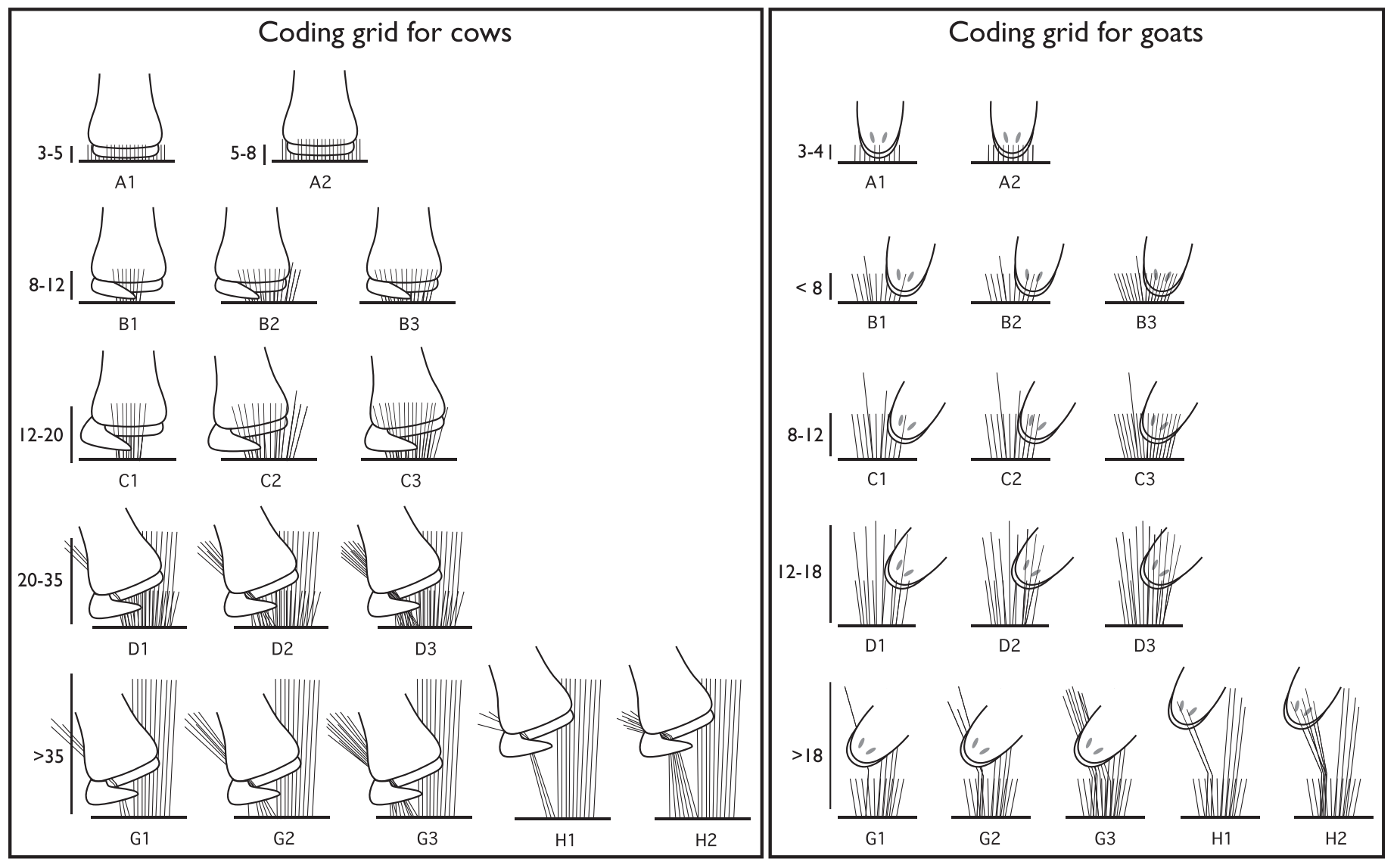

Figure 1. Species-specific coding grids for cows and goats used to classify bites into different bite types (adapted from Agreil and Meuret 2004). Bite types attempt to separate bites with regard to mass. We based these separations on differences in sward height, sward density, biting method, and bite size. Drawings represent the sward structure and the amount of grass taken by the herbivore in one bite. Sward height (cm) for all the bite types in a row appears on the left of each grid. Codes for each bite type appear below the drawings. Bites taken from the same sward height have the same code letter (e.g., B1, B2, B3). Higher letters in the alphabet represent bites taken in higher swards. Larger numbers in codes (e.g., D1, D2, D3) represent increases in bite size (i.e., number of leaves) from a same sward height.

differences in sward height, sward density, biting method, and bite size. Our grids differed to the one proposed by Agreil and Meuret (2004) in that we did not consider the nutritional value or plant structure in the categorization. Prior to data collection, each observer trained for $1 \mathrm{~d}$ with each species. Training consisted of first recognizing the bites and classifying them according to the coding grids. Once observers were comfortable with bite classification, they trained recording bites in real time and simulating them on the natural patches of grass.

Timing of the Experiment. One week prior to the experiment, we habituated the cows and goats to the experimental protocol and to the observers. After their day of training, each observer worked for two consecutive weeks, thus continuing the training throughout the experiment. Observers alternated their observations between cows and goats every $1 \mathrm{~d}$ or $2 \mathrm{~d}$. Each observer collected $5 \mathrm{~d}$ worth of data from the cows and $4 \mathrm{~d}$ to $5 \mathrm{~d}$ from the goats. Every morning prior to the experiment, we moved herbivores into individual pens where they had $a d$ lib access to water. While in the pens, we provided them with native grass hay. Observations began at 0900 hours and finished at 1300 hours. At the conclusion of the observation period, the herbivores were moved into natural rangelands for the rest of the day.
Description of the Trials. After preparing the natural patches of grass, we separated them into pairs that had similar sward heights and density. We designated one as the "feeding patch" and the other as the "simulation patch." A trial consisted of first presenting a feeding patch to one herbivore and recording its bites through direct observation. Secondly, the observer simulated the observed bites by hand plucking on the associated simulation patch. Before and after observations and simulations, we weighed each patch to the nearest $2 \mathrm{~g}$ to determine the amount consumed or plucked. Each observation and simulation took between $3 \mathrm{~min}$ and $10 \mathrm{~min}$.

Before starting a trial, we provided the herbivores with fresh hay to initiate their feeding. We then put the feeding patch on the ground and allowed the herbivore to feed from it. When working with cows, we firmly tied the patch on heavy bricks using nylon strings to prevent the cow from lifting and potentially damaging it while feeding. Depending on the size of the bites, we allowed cows to take between 8 and 20 bites, and goats 15 and 35 bites from each patch. Each observer recorded the number and the type of bites taken by the herbivore using the species-specific coding grids (Fig. 1).

Once the herbivore had taken the allowed number of bites, the observer then simulated the same type and number of bites on the associated simulation patch. For each simulation, we 
separated plucked bites by type and put them into separate paper bags. We then oven-dried these samples for $24 \mathrm{~h}$ at $60^{\circ} \mathrm{C}$ to determine the mean dry mass per bite type per trial. During the experiment, each observer performed between 30 and 40 trials with each of the herbivore species (six to eight trials per day for cows and 8 to 12 per day for goats). In total, we simulated 2120 bites for cows and 3788 for goats.

Estimation of the Evapotranspiration. Each day, we used two additional patches to estimate the loss in mass from the feeding and the simulation patches resulting from evapotranspiration. We weighed these patches to the nearest $2 \mathrm{~g}$ every $15 \mathrm{~min}$ throughout the period we ran the trials. We used the mean rate of mass loss between the two patches as our daily evapotranspiration rate (values ranged from $-0.17 \mathrm{~g} \cdot \mathrm{min}^{-1}$ to $\left.-0.59 \mathrm{~g} \cdot \min ^{-1}\right)$. To insure that the manner we measured evapotranspiration did not ultimately affect our bite mass estimates, we compared it to a potentially more precise method during half of the observation days. This method consisted of measuring the evapotranspiration of each feeding and simulation patches by weighing them every $15 \mathrm{~min}$ for $75 \mathrm{~min}$ prior to use. When we compared the two methods, we found that estimated mass loss did not differ (Person's chi-squared test, $\left.\chi^{2}=48906, P=0.25\right)$. As a result, we used the first method throughout the experiment.

\section{Calculation of the Accuracy}

For each trial, we calculated the accuracy of our bite mass estimates as:

Accuracy $=1-\frac{\mid \text { Amount grass plucked }- \text { Amount of grass eaten } \mid}{\text { Amount of grass eaten }}$

The amount of grass plucked by the observer and the amount of grass eaten by the herbivore correspond to the difference in mass of the simulation and the feeding patches, respectively, minus the estimated mass loss due to evapotranspiration. Because of the precision of the scale $( \pm 2 \mathrm{~g})$, we did not trust the measured difference in mass when the amount of grass eaten or plucked was very small. The variance in accuracy greatly expanded (from 0.03 to 0.19 ) when these amounts were inferior to $7.5 \mathrm{~g}$ or inferior to $10 \mathrm{~g}$ on windy days (as the scale accuracy was affected by the wind). As a result, we removed these data from the data set.

\section{Data Analysis}

We tested how different variables affected the accuracy of bite mass estimates using a multiway analysis of variance (ANOVA) with a linear model. Covariates included the number of days the observer was trained with the herbivore species (Training) and the overall mean weight (wet matter) of the bites taken by the herbivore during one trial (Mean bite weight). Factors included the identity of the observer (Observer) and the herbivore species used (Species). Accuracy, as a proportion, was arcsine-transformed, whereas we log-transformed mean bite weight to obtain homoscedasticity and normal distribution of the residuals. We tested how different factors affected the dry mass of the simulated bites for each species using two-way ANOVAs with linear models. In order to avoid confusing the results with inaccurate simulations made by untrained observ- ers, we only considered the data collected by each observer during their last $2 \mathrm{~d}$ of observation. Factors included the bite type and the observer. The dry mass of the bites was logtransformed. For all the above models, we systematically removed nonsignificant interactions during the model simplification procedure. Finally, we calculated the over- or underestimation of the amount of grass eaten by the herbivore using a similar equation as for the calculation of accuracy. However, in this instance we used the true value of the error rather than its absolute value. All analyses were conducted on R 2.7.0 GUI (R Development Core Team 2010).

\section{RESULTS}

\section{Accuracy of the Hand Plucking Method}

The relationship between the amount of grass eaten by an herbivore and the amount of grass plucked by the observer was linear for both cows (Fig. 2a) and goats (Fig. 2b). On the last day of training (Fig. 2, solid circles), the slope of the relationship was not significantly different from one for either cows (estimate $=0.993, \mathrm{SE}=0.049, n=27$ ) or goats (estimate $=0.851, \mathrm{SE}=0.148, n=40$ ).

Training of the observer was the most important variable influencing the accuracy of bite mass estimates (Table 1 ). The mean accuracy per observer increased from $60 \%$ to $80 \%$ on the first day to $80 \%$ to $94 \%$ on the final day for both cows and goats (Fig. 3). The slope of the relationship between training and accuracy was not affected by either the observer identity $(P=0.97)$ or the herbivore species $(P=0.16)$. Finally, the mean weight of the bites taken by the herbivore during one trial did not affect the accuracy of the simulations (Table 1). This indicates that the difficulty of simulating bites did not differ between large and small bites.

\section{Bias of the Measurements}

On the first day of observation, observers generally underestimated the amount of grass eaten per patch for cows $($ mean $=25 \%)$ and overestimated it for goats $($ mean $=18 \%)$. But after $5 \mathrm{~d}$ of training, bite mass estimations improved to where they centered on the real values, indicating an absence of bias (nonsignificant underestimation of $1.4 \%$ for cow, $P=0.60$; and nonsignificant overestimation of $2.2 \%$ for goat, $P=0.52$ ).

\section{Interobserver and Interspecies Variability}

The interaction between observer and herbivore species had a significant effect on the accuracy of bite mass estimations (Table 1). For example, observer 1 was better at estimating bite mass of cows at the beginning of the experiment than the other observers (Fig. 3). In addition, observers 2 and 4 were better at estimating the bite mass of goats than observers 1 and 3 (Fig. 3). This effect, however, disappeared by the final day of training when all observers were equally able to estimate the bite masses of both cattle and goats (observer $\times$ species effect: $P=0.86)$.

\section{Differences in Mass Between Bite Types}

Bite type explained $79 \%$ of the total variance in the dry mass of the simulated bites for cows and $58 \%$ for goats (Table 2). 


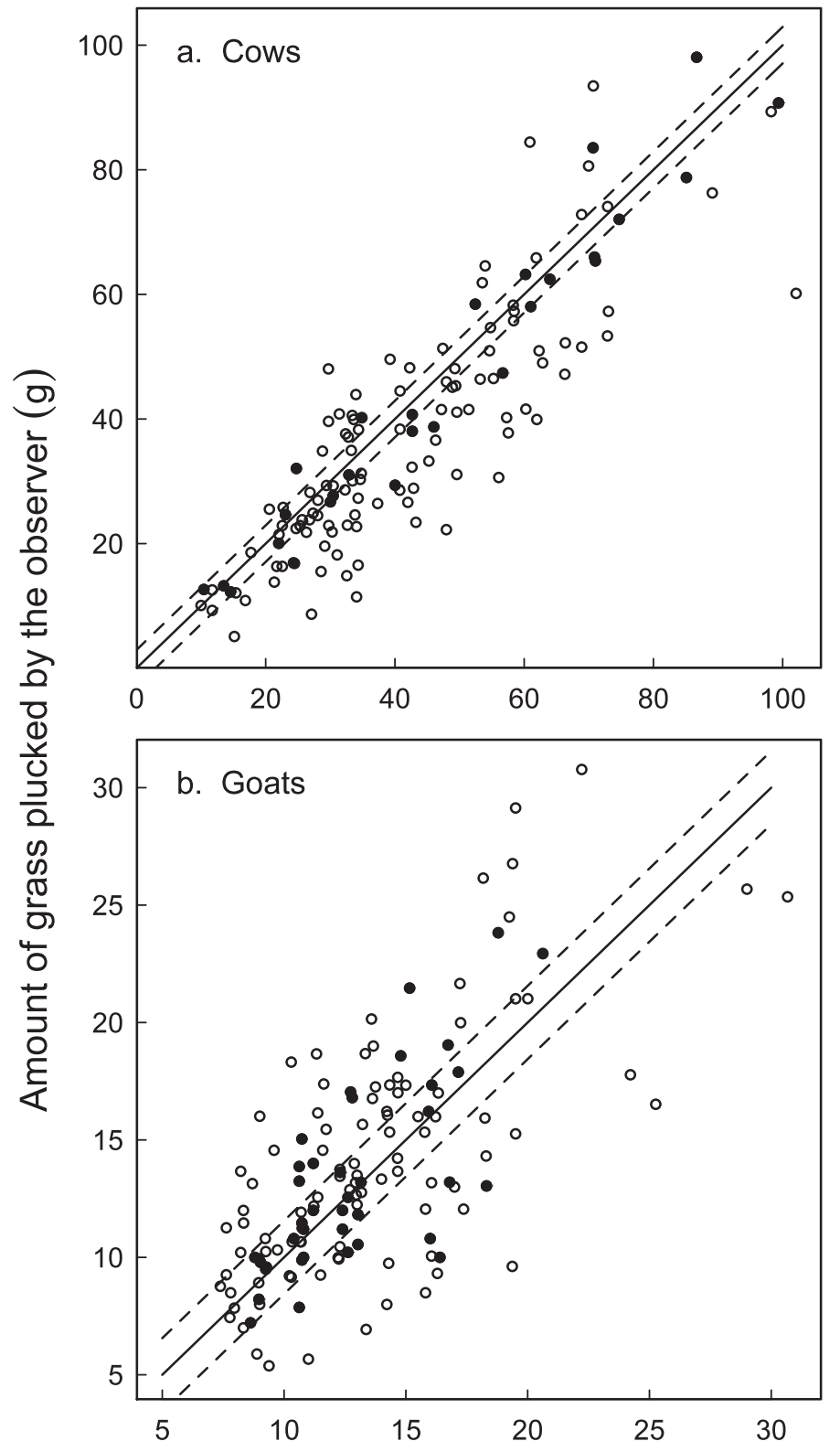

Amount of grass eaten by the animal $(\mathrm{g})$

Figure 2. Relationship between the amount of grass eaten by the herbivore on a feeding patch ( $g$ wet matter) and the amount of grass plucked by the observer on the equivalent simulation patch ( $g$ wet matter) for both (a) cows and (b) goats. Solid circles represent data from the final day of observation by each observer, when they were fully trained. Solid lines are the identity lines $(Y=X)$. Dashed lines represent the confidence interval of the measurements with regard to scale precision $( \pm 2 \mathrm{~g})$. The relationship is plotted on a larger scale for goats than for cows.

Different bite types of the same sward height (e.g., C1, C2, and C3) were well separated according to their differences in dry mass (Fig. 4). On the contrary, bites from different sward heights sometimes had large overlaps in their distribution in dry mass, particularly with goats (Fig. 4b). For example, bites of the same size but of different sward heights (e.g., B1, C1, and D1) varied little according to dry mass. Observers also varied with respect to the mean bite mass they assigned to each of
Table 1. Result of the multiway ANOVA of the variables affecting the accuracy of bite mass estimates.

\begin{tabular}{lrrrr}
\hline Source of variation & df & SS $^{3}$ & $F$ & $P$ \\
\hline Training $^{1}$ & 1 & 0.975 & 24.84 & $<0.001$ \\
Observer & 3 & 0.097 & 0.82 & 0.483 \\
Species & 1 & 0.060 & 1.53 & 0.217 \\
Mean bite weight $^{2}$ & 1 & 0.041 & 1.04 & 0.309 \\
Observer $\times$ species $_{\text {Residuals }}$ & 3 & 0.542 & 4.60 & 0.004 \\
\hline
\end{tabular}

${ }^{1}$ Number of days the observer was trained with the herbivore species.

${ }^{2}$ Mean weight (wet matter) of the bites taken by the herbivore on the feeding patch during one trial.

${ }^{3}$ Sum of square.

these categories (Table 2, observer $\times$ bite type effect). Ultimately, this suggests that different observers did not always assign bites of similar mass into the same bite type. This effect, however, was limited as it only explained $9 \%$ of the total variance in the dry mass of the simulated bites for cows and $17 \%$ for goats (Table 2).

\section{DISCUSSION}

Previous studies have often criticized hand plucking as a method of estimating herbivore food intake in rangelands suggesting it is subjective and lacks accuracy (e.g., Jiang and Hudson 1992; Gordon 1995; Forbes 2006). However, our study demonstrates that such concerns can be dismissed with observer training. After only $5 \mathrm{~d}$ of training per species, all four observers were able to estimate bite masses of cows and goats grazing on heterogeneous vegetation with accuracies over $80 \%$. More importantly, these estimations were unbiased and individual observers did not differ in their level of accuracy. In addition, despite suggestions to the contrary (Wallis de Vries 1995; Decruyenaere et al. 2009), we found that it was not easier to simulate bites of large herbivores (e.g., cattle) compared to those of smaller ones (e.g., goats).

Our study stresses the importance of observer training in achieving accurate bite mass measurements. With limited training, the ability of the different observers to accurately estimate individual bite mass was poor. However, after as little as $5 \mathrm{~d}$ of training, their accuracy increased to where it was over $80 \%$. It is possible that we could have improved on this if the observers had focused on one species rather than switching between species. After training for $5 \mathrm{~d}$, bite mass measurements were centered on the real values (i.e., unbiased). As a result, positive and negative errors on the estimates will tend to cancel each other out when we combine measurements. For example, we generated the estimates of intake cumulated over the 6 to 12 trials conducted by each observer during their final day of observation. We did this by summing all bite mass measurements made during that day. When we compared these estimates with the real values, we found that the accuracy for intake ranged between $94.4 \%$ and $99.4 \%$. This indicates that one can achieve accurate measurements of instantaneous intake by hand plucking once a sufficient number of individual measurements are combined. In our example, it only took combining the intake over 6 to 12 feeding stations (i.e., trials) 


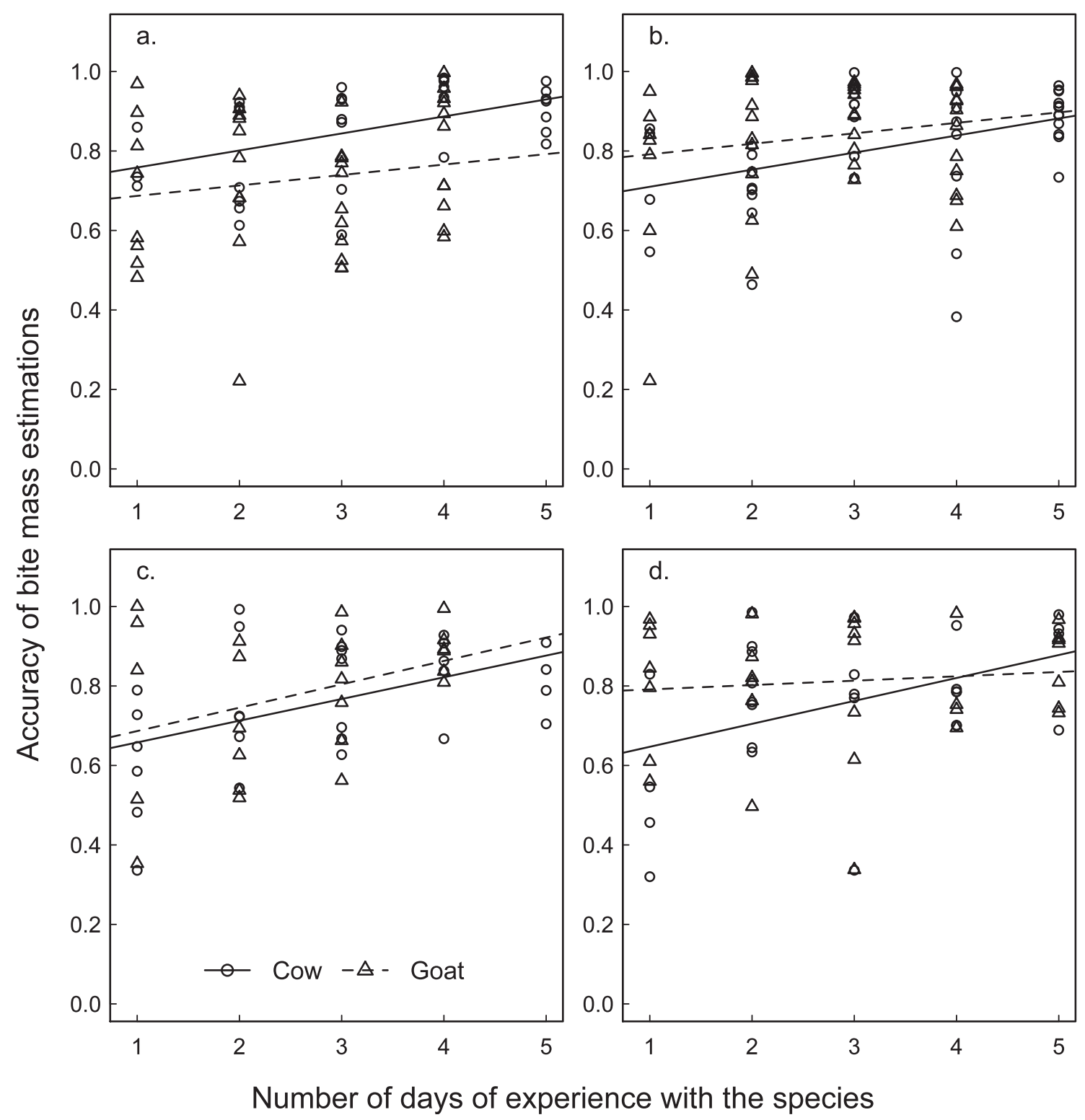

Figure 3. Accuracy of bite mass estimations as a function of the number of days of training with both cows (circles) and goats (triangles). The four figures are from the four observers (a-d for observers 1 through 4, respectively). Plotted lines (plain for cows and dotted for goats) are the linear regressions minimizing deviance of the fitted values.

to achieve these levels of accuracy. Therefore, if we consider daily intake, then our results suggest that the use of hand plucking can lead to even better results, as a much larger number of measurements are combined (see Agreil et al. 2006).

These findings contrast with previous studies that concluded hand plucking generally overestimates daily intake (e.g., Renecker and Huson1985; Jiang and Hudson 1992; Gedir and Hudson 2000). These studies calculated daily intake as the product of bite mass, bite rates, and grazing time. However, short-term measurements of bite rates (often recorded during grazing activity peaks and for less than $2 \mathrm{~min}$ ) generally overestimate long-term mean bite rates (e.g., for an entire day; e.g., Jamieson and Hodgson 1979; Forbes and Hodgson 1985). As a result, we propose that these errors, rather than biased bite mass measurements, probably caused the overestimations of daily intake in the previous studies.
We observed a linear relationship between the amount of grass eaten by the herbivore and the amount collected by hand plucking. In contrast, Wallis de Vries (1995) reported a curvilinear relationship between intake of steers measured using the esophageal fistulation and hand plucking methods. However, in his study, Wallis de Vries used the bite mass per unit biting area rather than the actual bite mass for his esophageal fistulation data. As the experiment extended for $2 \mathrm{yr}$, the biting area of the steers significantly increased (see fig. 1 in Wallis de Vries 1995). Consequently, it is likely that larger bites were associated with larger biting areas. By dividing small bites by a small biting area and larger bites by a larger biting area, the relationship becomes curvilinear. If Wallis de Vries (1995) had used actual bite mass rather than bite mass per unit biting area for his fistulation measurements, he would have probably obtained a linear relationship. 
Table 2. Results of the two-way ANOVAs of the factors affecting the dry mass of the simulated bites for cows (A) and goats (B), respectively. Only the data collected during the last $2 \mathrm{~d}$ of observation by each observer were considered.

\begin{tabular}{|c|c|c|c|c|}
\hline Source of variation & $d f$ & $S S^{2}$ & $F$ & $P$ \\
\hline A. Bite type $e^{1}$ & 15 & 108.4 & 81.24 & $<0.001$ \\
\hline Observer $\times$ bite type & 35 & 12.5 & 4.02 & $<0.001$ \\
\hline Residuals & 192 & 17.1 & - & - \\
\hline B. Bite type ${ }^{1}$ & 15 & 105.8 & 49.28 & $<0.001$ \\
\hline Observer $\times$ bite type & 40 & 30.9 & 5.39 & $<0.001$ \\
\hline Residuals & 316 & 45.2 & - & - \\
\hline
\end{tabular}

${ }^{1}$ As defined in Figure 1.

${ }^{2}$ Sum of square.

A frequent criticism directed towards hand plucking is the nonrepeatability of bite mass estimations between observers (e.g., Langlands 1974; Gordon 1995; Forbes 2006). Surprisingly, we could not find any studies that tested the repeatability of hand plucking measurements among observers. Indeed, studies using hand plucking generally involved only one observer, and thus did not determine repeatability (e.g., Collins and Urness 1983; Hobbs et al. 1983; Agreil and Meuret 2004). Furthermore, the two studies that involved more than one observer did not find significant differences in the bite mass estimates of the different observers (Hudson and Nietfeld 1985; Hudson and Watkins 1986). By using four different observers with varying degrees of experience, our experiment provides a more robust test of repeatability. At the onset of the experiment, the four observers differed in their relative ability to simulate bite masses. However, these differences quickly disappeared with training.

One aspect that likely led to the high degree of repeatability between observers was the use of standardized coding grids. Original papers on hand plucking emphasized the importance of categorizing bites according to plant species and plant parts consumed (Halls 1954; Cook 1964). However, the common practice has been to estimate an "average bite size" by pooling together samples of the different plant species and plant parts consumed by the herbivore over several minutes (e.g., Langlands 1974; Hudson and Nietfeld 1985; Jiang and Hudson 1992; Okello et al. 2002). Meuret et al. (1985), then Wallis de Vries (1995), stressed the lack of accuracy of such mixed samples and re-emphasized the importance of stratified sampling. To facilitate such stratification, Agreil and Meuret (2004) developed a detailed coding grid that separate bites according to mass, structural composition, and expected nutritional value of the removed material. The categorization of the bites in different types probably helped observers in our study to simulate bites as close as possible to the observed ones.

In field studies, observation conditions and vegetation heterogeneity may affect the accuracy of bite mass estimations (Gordon 1995). However, using a detailed coding grid can help minimize the problems related to vegetation heterogeneity. Challenging observation conditions, such as dense thickets areas, are more problematic. When working with domestic or tame herbivores, animals can easily be observed at short distances (i.e., less than $2 \mathrm{~m}$ ) without being disturbed, ensuring excellent observation conditions (e.g., Bryant et al. 1980;

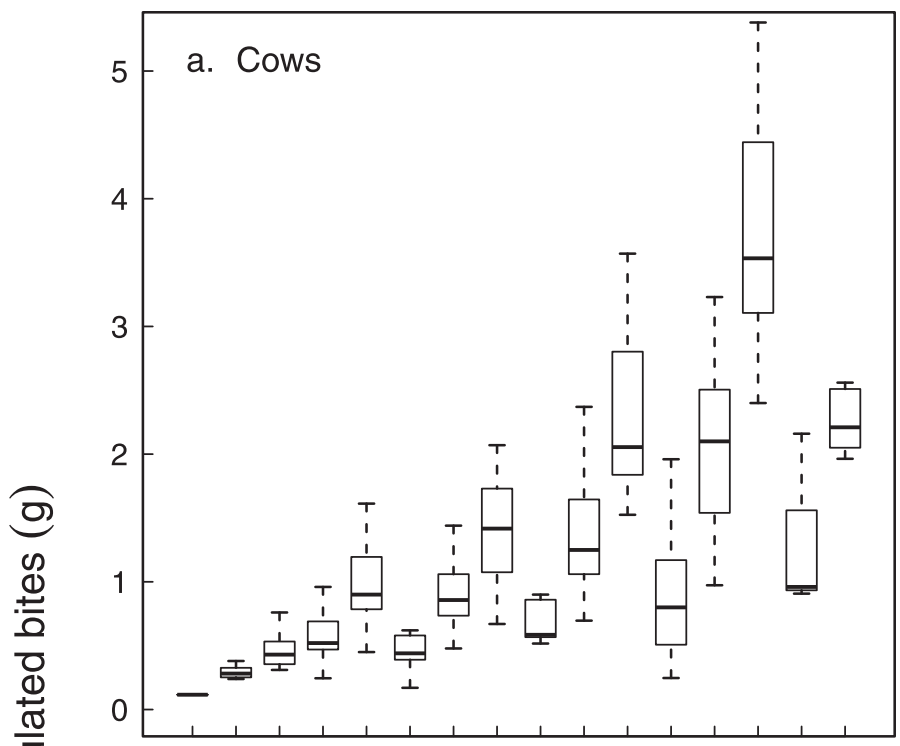

A1 A2 B1 B2 B3 C1 C2 C3 D1 D2 D3 G1 G2 G3 H1 H2

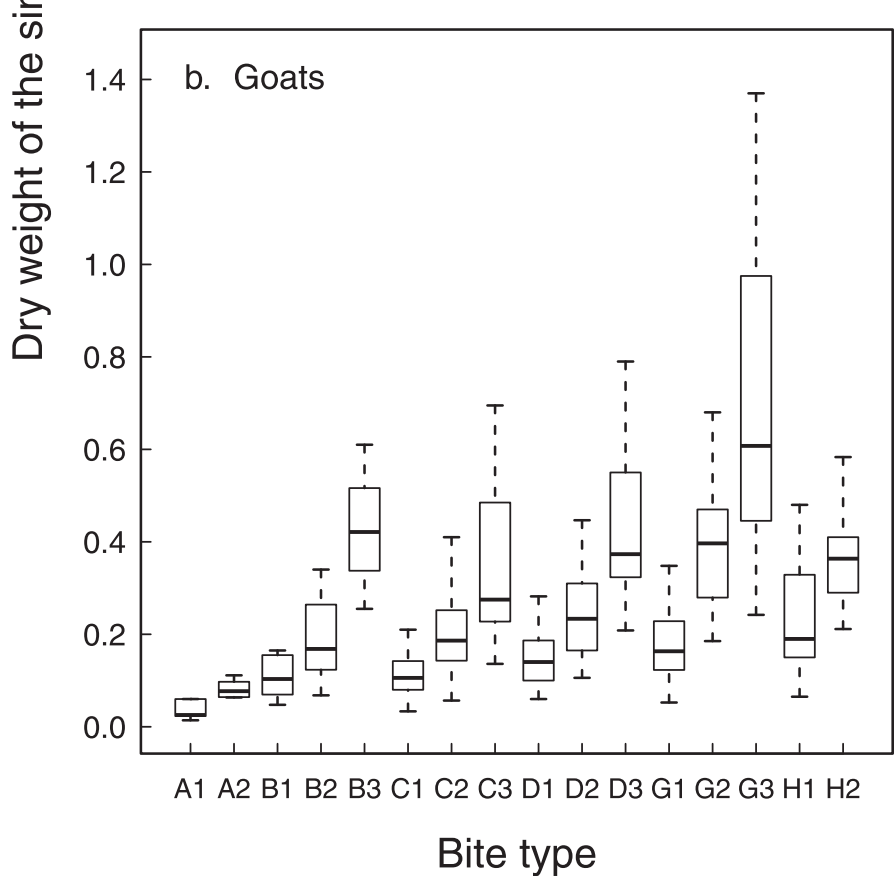

Figure 4. Mass of the simulated bites ( $g$ dry matter) as a function of bite types for (a) cows and (b) goats. Only the data collected during the last $2 \mathrm{~d}$ of observation (i.e., when observers were fully trained) are presented. Bite types are defined in Figure 1. For each bite type, horizontal lines indicate the median values, boxes include the central $50 \%$ of the distribution, and vertical dashed lines the central $95 \%$ of the distribution.

Hobbs et al. 1983; Agreil and Meuret 2004). Sometimes, wild herbivores can be habituated to humans or vehicles and observed in close proximity (e.g., Hudson and Frank 1987). However, many studies involve wild, nonhabituated herbivores. The method can still be used but may require observations to be made at a greater distance to avoid disturbing the herbivore (i.e., $20 \mathrm{~m}$ to $60 \mathrm{~m}$; Okello et al. 2002; Shrader et al. 2006). In these conditions, it is recommended to carefully examine the imprints of the bites observed before simulating them. 


\section{IMPLICATIONS}

This study shows that hand plucking is a reliable way to estimate food intake in grazing herbivores. This result is of importance as hand plucking is often the only feasible method to measure bite mass and instantaneous intake of herbivores grazing on rangelands, and because of previous criticisms of the method. With training, observers can estimate bite masses with accuracy over $80 \%$ and instantaneous intake over about 10 feeding stations with accuracy over $95 \%$. In this experiment, we reached high levels of accuracy after only $5 \mathrm{~d}$ of training. However, we would suggest $7 \mathrm{~d}$ to $10 \mathrm{~d}$ of training prior to fieldwork, especially if one is studying herbivores feeding in heterogeneous habitats. It is also important to note that the coding grids used in this study were specific to our experimental conditions and thus may not apply with other herbivore species or vegetation types. Therefore, we recommend that other studies develop new grids during preliminary observations. Hand plucking is particularly suitable to field studies because it is simple and does not require manipulation of monitored individuals. It is, however, time consuming and only one individual can be observed at the time, which may limit large-scale studies. Combining hand plucking with indirect (i.e., markers) or automated recording (i.e., activity sensors) methods, which produce a larger but less detailed data set, may prove to be very useful to understanding the foraging strategies and land use of free-ranging herbivores.

\section{ACKNOWLEDGMENTS}

We thank V. D. Ngdi and the staff of the URF for their help during the experiment, and the Department of Animal Science for the use of their cattle and goats. We also thank P. Duncan, G. Fleurance, and N. Edouard for their advice concerning the planning of this experiment, J.-L. Janeau for sharing his scale, and two anonymous referees for their insightful comments on this manuscript.

\section{LITERATURE CITED}

Agrell, C., And M. Meuret. 2004. An improved method for quantifying intake rate and ingestive behaviour of ruminants in diverse and variable habitats using direct observation. Small Ruminant Research 54:99-113.

Agrell, C., M. Meuret, and H. Fritz. 2006. Adjustment of feeding choices and intake by a ruminant foraging in varied and variable environments: new insights from continuous bite monitoring. In: V. Bels [ED.]. Feeding in domestic vertebrates-from structure to behaviour. Oxfordshire, United Kingdom: CAB International. p. 302-325.

Bryant, F. C., M. M. Kothmann, and L. B. Merrill. 1980. Nutritive content of sheep, goat, and white-tailed deer diets an excellent condition rangeland in Texas. Journal of Range Management 33:410-414.

Burns, J. C., K. R. Pond, And D. S. Fisher. 1994. Measurement of forage intake. In: G. F. J. Fahey, M. Collins, D. R. Mertens, and L. E. Moser [EDs.]. Forage quality, evaluation and utilization. Lincoln, NE, USA: American Society of Agronomy. p. 494-532.

Collins, W. B., and P. J. Urness. 1983. Feeding behavior and habitat selection of mule deer and elk on northern Utah summer range. Journal of Wildlife Management 47:646-663.

Cook, C. W. 1964. Symposium on nutrition of forages and pastures: collecting forage samples representative of ingested material of grazing animals for nutritional studies. Journal of Animal Science 23:265-270.
Cordova, F. J., J. D. Wallace, and R. D. Pieper. 1978. Forage intake by grazing livestock: a review. Journal of Range Management 31:430-438.

Decruyenaere, V., A. Buldgen, and D. Stilmant. 2009. Factors affecting intake by grazing ruminants and related quantification methods: a review. Biotechnologie Agronomie Societe et Environnement 13:559-573.

Dove, H., AND R. W. Mayes. 1996. Plant wax components: a new approach to estimating intake and diet composition in herbivores. Journal of Nutrition 126:13-26.

Fleurance, G., H. Fritz, P. Duncan, I. J. Gordon, N. Edouard, and C. Vial. 2009. Instantaneous intake rate in horses of different body sizes: influence of sward biomass and fibrousness. Applied Animal Behaviour Science 117:84-92.

FoRBES, J. M. 1995. Voluntary food intake and diet selection in farm animals. 0xon, United Kingdom: CAB International. 532 p.

Forbes, J. M. 2006. Conclusion and perspectives. In: V. Bels [ED.]. Feeding in domestic vertebrates-from structure to behaviour. Oxfordshire, United Kingdom: CAB International. p. 349-358.

Forbes, T. D. A., And J. Hodgson. 1985. Comparative studies of the influence of sward conditions on the ingestive behaviour of cows and sheep. Grass and Forage Science 40:69-77.

GEDIR, J. V., AND R. J. Hudson. 2000. Seasonal intake determination in reproductive wapiti hinds (Cervus elaphus canadensis) using n-alkane markers. Canadian Journal of Animal Science 80:137-144.

Gordon, I. J. 1995. Animal-based techniques for grazing ecology research. Small Ruminant Research 16:203-214.

HaLLS, L. K. 1954. The approximation of cattle diet through herbage sampling. Journal of Range Management 7:269-270.

HobBs, N. T., D. L. BakeR, and R. B. Gill. 1983. Comparative nutritional ecology of montane ungulates during winter. Journal of Wildlife Management 47:1-16.

Hudson, R. J., and S. Frank. 1987. Foraging ecology of bison in aspen boreal habitats. Journal of Range Management 40:71-75.

Hudson, R. J., and M. T. Nietfeld. 1985. Effect of forage depletion on the feeding rate of wapiti. Journal of Range Management 38:80-82.

Hudson, R. J., AND W. G. Watkins. 1986. Foraging rates of wapiti on green and cured pastures. Canadian Journal of Zoology 64:1705-1708.

Illius, A. W., and I. J. Gordon. 1987. The allometry of food intake in grazing ruminants. Journal of Animal Ecology 56:989-999.

Jamieson, W. S., AND J. Hodgson. 1979. The effect of daily herbage allowance and sward characteristics upon the ingestive behaviour and herbage intake of calves under strip-grazing management. Grass and Forage Science 34:261-271.

JiAng, Z., AND R. J. Hudson. 1992. Estimating forage intake and energy requirements of free-ranging wapiti (Cervus elaphus). Canadian Journal of Zoology 70:675-679.

LanglandS, J. P. 1974. Studies on nutritive value of diet selected by grazing sheep. 7. A note on hand plucking as a technique for estimating dietary composition. Animal Production 19:249-252.

Le Du, Y. L. P., and P. D. Penning. 1982. Animal based techniques for estimating herbage intake. In: J. D. Leaver [ED.]. Herbage intake handbook. Hurley, Maidenhead, Berkshire, United Kingdom: The British Grassland Society. p. 37-75.

Leaver, J. D. 1982. Herbage intake handbook. Hurley, Maidenhead, Berkshire, United Kingdom: The British Grassland Society. 143 p.

Mayes, R. W., AND H. Dove. 2000. Measurement of dietary nutrient intake in freeranging mammalian herbivores. Nutrition Research Reviews 13:107-138.

Mayes, R. W., C. S. Lamb, and P. M. Colgrove. 1986. The use of dosed and herbage n-alkanes as markers for the determination of herbage intake. Journal of Agricultural Science 107:161-170.

Meuret, M., N. Bartiaux-Thill, and A. Bourbouze. 1985. Feed-intake of dairy goats on rangelands-direct observation of biting method—chromic oxide method. Annales de Zootechnie 34:159-179.

Okelto, M. M., R. E. L. Wishitemi, And F. Muhoro. 2002. Forage intake rates and foraging efficiency of free-ranging zebra and impala. South African Journal of Wildlife Research 32:93-100.

R Development Core Team. 2010. R: a language and environment for statistical computing. Vienna, Austria: R Foundation for Statistical Computing, Available at: http://www.R-project.org/. Accessed 1 February 2011. 
Renecker, L. A., and R. J. Hudson. 1985. Estimation of dry matter intake of freeranging moose. Journal of Wildlife Management 49:785-792.

Shipley, L. A., J. E. Gross, D. E. Spalinger, N. T. Hobbs, and B. A. Wunder. 1994. The scaling of intake rate in mammalian herbivores. American Naturalist 143:1055-1082.

Shrader, A. M., N. Owen-Smith, and J. 0. Ogutu. 2006. How a mega-grazer copes with the dry season: food and nutrient intake rates by white rhinoceros in the wild. Functional Ecology 20:376-384.

SinclaiR, A. R. E. 1975. The resource limitation of trophic levels in tropical grassland ecosystems. Journal of Animal Ecology 44:497-520.

Spalinger, D. E., AND N. T. HobBs. 1992. Mechanisms of foraging in mammalian herbivores: new models of functional response. American Naturalist 140:325-348.
Stephens, D. W., and J. R. Krebs. 1986. Foraging theory. Princeton, NJ, USA: Princeton University Press. $262 \mathrm{p}$.

StoвBS, T. H. 1973. The effect of plant structure on the intake of tropical pastures. 1. Variation in the bite size of grazing cattle. Australian Journal of Agricultural Research 24:809-819.

ToreLL, D. T. 1954. An esophageal fistula for animal nutrition studies. Journal of Animal Science 13:878-884.

Vulich, S. A., J. P. Hanrahan, and E. G. O'Riordan. 1993. Pasture sampling for the estimation of herbage intake using n-alkanes: evaluation of alternative sampling procedures. Irish Journal of Agricultural and Food Research 32:1-11.

WaLLIS DE VRIES, M. F. 1995. Estimating forage intake and quality in grazing cattle: a reconsideration of the hand-plucking method. Journal of Range Management 48:370-375 